\title{
Sleep Quality in Patients With Type 2 Diabetes Mellitus
}

\author{
Safa Barakat ${ }^{\mathrm{a}}$, Mousa Abujbara ${ }^{\mathrm{a}}$, Radwan Banimustafa ${ }^{\mathrm{b}}$, \\ Anwar Batieha ${ }^{\mathrm{c}}$, Kamel Ajlounia, d
}

\begin{abstract}
Background: This study aims to evaluate the sleep quality in patients with type 2 diabetes mellitus (T2DM), and to assess the relevance of other factors to sleep quality.

Methods: A cross-sectional study was carried out at the National Center for Diabetes, Endocrinology and Genetics (NCDEG) in Amman, Jordan, during the period from October 1, 2015 to December 31, 2015. A total of 1,211 (540 male and 671 female) patients with T2DM were recruited. Data were collected using the Pittsburgh sleep quality index (PSQI) to assess the sleep quality with a cutoff point of PSQI $\geq 8$. Participants' demographic background data were also recorded. Statistical analysis was conducted using SPSS version 22 .
\end{abstract}

Results: The mean age of our patients was $58.8 \pm 9.74$ years. Mean body mass index (BMI) was $32.67 \pm 6.1 \mathrm{~kg} / \mathrm{m}^{2}$, and mean duration of diabetes was $10.3 \pm 7.38$ years. The mean PSQI score was $10.2 \pm$ 3.10 . In the present study, poor sleep quality was reported in $81 \%$ of participants. Multivariate logistic regression analysis revealed that poor sleep quality was significantly associated with high $\mathrm{HbAlc}$, female gender, smoking, unemployment, and insulin use. The study showed that subjective sleep quality and quantity, night sleep disturbance, and daytime dysfunction were risk factors for poor glycemic control.

Conclusions: In our series, patients with T2DM (81\%) have poor sleep quality. Females, smokers, unemployed individuals, insulin users and patients with uncontrolled diabetes seem to be significantly at higher risk of poor sleep quality.

Keywords: Sleep quality; Diabetes mellitus; HbA1c; Daytime dysfunction

Manuscript submitted January 29, 2017, accepted February 13, 2017

aThe National Center (Institute) for Diabetes, Endocrinology and Genetics/ University of Jordan, Amman, Jordan

bDepartment of Psychiatry, the University of Jordan, Amman, Jordan

'Department of Community Medicine, Public Health and Family Medicine, Faculty of Medicine, Jordan University of Science and Technology, Irbid 22110, Jordan

${ }^{\mathrm{d} C o r r e s p o n d i n g ~ A u t h o r: ~ K a m e l ~ A j l o u n i, ~ T h e ~ N a t i o n a l ~ C e n t e r ~(I n s t i t u t e) ~ f o r ~}$ Diabetes, Endocrinology and Genetics/University of Jordan, PO Box 13165, Amman 11942, Jordan. Email: ajlouni@ju.edu.jo

doi: https://doi.org/10.14740/jocmr2947w

\section{Introduction}

Diabetes mellitus is a widespread disease, associated with rapid social and cultural changes, such as aging of population, urbanization, dietary changes, reduced physical activity, and unhealthy behaviors, leading to lower quality of life and decreased survival of affected individuals $[1,2]$.

Studies in Jordan reported high rates of diabetes and impaired fasting glucose (IFG) that are still increasing. Ajlouni et al (1998) reported the prevalence of type 2 diabetes mellitus (T2DM) at $13.4 \%$ and the prevalence of IFG at 9.8\% [3]. The national study, in 2008, found T2DM and IFG in Jordan were prevalent at $17.1 \%$ and $17.8 \%$, respectively [4].

Sleep is a period of physical and mental recess. As an indispensable human need, sleep is vital for good health and quality of life [5]. However, sleep disturbances, environmental unrest, as well as mood disorders adversely affect quality of sleep [6]. The National Sleep Foundation (2015) recommends 7 - 9 h of sleep durations for adults between 26 and 64 years on average. Recommended duration of sleep, however, decreases with increase in age [7-9]. Findings from three separate studies indicate that sleeping five or fewer hours per night may boost mortality risk by $15 \%$ [10]. In addition, short sleep ( $\leq 6 \mathrm{~h} /$ day) was associated with glucose intolerance and insulin resistance [10-13], as well as an elevation in the incidence of diabetes [14-16]. Also, long sleep ( $\geq 9 \mathrm{~h} /$ day) increased the risk of developing diabetes [17]. Inefficient sleep duration was reported, in the past few years, to underlie adverse health consequences, such as obesity, diabetes, hypertension, cardiovascular diseases (CVDs) and increased mortality [18, 19].

Previous studies have shown that sleep is one of the most important factors in life, and it has impact on many metabolic aspects including glucose tolerance [20,21]. It is, therefore, important for diabetic patients to have proper sleep periods to better control their diabetes [21].

\section{Materials and Methods}

A cross-sectional study was conducted between October 1, 2015 and December 31, 2015 on diabetic patients attending the National Centre for Diabetes, Endocrinology and Genetics (NCDEG).

All patients $\geq 18$ years of age with T2DM duration more than 1 year, and attending the NCDEG during the study period were included in the study. Patients were excluded if they had T1DM, gestational diabetes, severe heart diseases, lung dis- 
eases, cerebral diseases, prior treatment for obstructive sleep apnea (OSA), continuous positive airway pressure (CPAP) or surgery, and cognitive impairment.

The study was approved by the NCDEG. A total of 1,211 patients with T2DM were included in the study.

The Arabic version of the PSQI is a 19-item self-administered questionnaire that evaluates sleep quality [22]. The 19 items comprise seven factors: subjective sleep quality, sleep latency, sleep duration, habitual sleep efficiency, sleep disturbances, use of sleep medications, and daytime dysfunction. Each factor was equally weighed on a $0-3$ scale. The total score ranges from 0 to 21 , with higher scores denoting the worst sleep quality. A cutoff score of 8 was used in this study to mark poor sleepers $(\geq 8)$ from good sleepers $(<8)$. The Arabic version of the PSQI proved to be a reliable and valid instrument [23], with $98.3 \%$ sensitivity and $90.2 \%$ specificity [17].

Recruited patients, who were assured of complete privacy, were asked to complete the questionnaire. Additional data on each patient were collected from medical records.

The Statistical Package for Social Sciences (SPSS, version 22) was used to carry out the statistical analysis.

Descriptive statistics, which included mean and standard deviation (SD) and proportions were obtained for relevant variables. Testing for statistical significance of differences was performed using the independent $t$-test for continuous variables and the Chi-square test for categorical variables. Additionally, in order to examine the independent effect of the variables of interest, the researcher used multivariate logistic regression. A P-value of 0.05 was considered as statistically significant.

\section{Results}

Overall, 1,211 individuals with more than half of them were females have participated in the study. Age ranged from 22 to 86 years with a mean of 58.8 (SD: 9.74). The majority $81.6 \%$ ( $\mathrm{n}=988$ ) were married. Patients' average body mass index (BMI) was $32.67 \mathrm{~kg} / \mathrm{m}^{2}$ (SD: 6.1). In the sample, 88 patients $(7.3 \%)$ were of normal BMI (18.5 - $\left.24.99 \mathrm{~kg} / \mathrm{m}^{2}\right), 345(28.5 \%)$ were overweight (BMI: $25-29.9 \mathrm{~kg} / \mathrm{m}^{2}$ ), and the remaining $778(64.2 \%)$ were obese $\left(\mathrm{BMI} \geq 30 \mathrm{~kg} / \mathrm{m}^{2}\right)$. The mean diabetes duration was 10.3 years (SD: 7.38). Patients on oral treatment were $610(50.4 \%)$. Unemployed or retired participants comprised $68.8 \%, 3.1 \%$ had part-time employment, and $28.2 \%$ were in full-time employment. Current smokers made up $24.9 \%$ of the participants, whereas $6.9 \%$ were ex-smokers and $68.2 \%$ were non-smokers. There were $70 \%$ with uncontrolled HbA1c $(\geq 7)$. The mean PSQI score of the study patients was 10.2 (SD: 3.10$)$, with $81.0 \%(\mathrm{n}=981)$ having a PSQI score of $\geq 8$, indicating poor quality of sleep.

The global score of PSQI divided participants into good sleepers (PSQI $<8$ ) and poor sleepers (PSQI $\geq 8$ ). As Table 1 shows, sleep quality was significantly related to gender, BMI, marital status, HbA1c, diabetes duration, type of diabetic medications, and occupational status.

Logistic regression analyses were conducted to identify factors independently related to sleep quality, as shown in Table 2. Each variable in this table was adjusted for all other variables in the table.

Females were 2.88 times more likely to have poor sleep than males $(\mathrm{OR}=2.88, \mathrm{P}<0.001)$. In addition, smokers were significantly more likely to be poor sleepers compared to nonsmoker $(\mathrm{OR}=1.92, \mathrm{P}=0.001)$.

Unemployed subjects were significantly more likely to have poor sleep than full-time employed subjects $(\mathrm{OR}=1.69$, $\mathrm{P}=0.007)$. Part-time employed subjects were at higher risk of poor sleep, but the association was not statistically significant $(\mathrm{OR}=1.71, \mathrm{P}=0.25)$. Patients on insulin therapy were significantly more likely to have poor sleep than patients on OHA treatment $(\mathrm{OR}=2.17, \mathrm{P}<0.001)$. In addition, uncontrolled HbA1c subjects had a significantly higher likelihood of having poor sleep than controlled $\mathrm{HbA} 1 \mathrm{c}$ subjects with $(\mathrm{OR}=2.13, \mathrm{P}$ $<0.001)$.

\section{Discussion}

This study is the first in Jordan to assess sleep quality among a relatively large sample of patients with T2DM using the PSQI questionnaire.

Quality of sleep is an important constituent of quality of life. Poor sleep conjugates with depression, anxiety, impaired social functioning, chronic medical conditions, and mortality.

Around $10 \%$ of people complain of one form of sleep disorders. This is particularly common in patients with diabetes mellitus $[24,25]$, where poor quality of sleep significantly increases morbidity and mortality [26].

\section{Poor sleep quality prevalence in patients with T2DM at the NCDEG}

Using PSQI scores with cutoff point global PSQI $\geq 8$ for sleep evaluation in our study, we found that $81.0 \%$ of T2DM patients suffer from poor sleep quality. However, other studies, which investigated this issue in diabetic patients, reported lower rates than ours. For example, Vigg et al's cross-sectional study, in which the cutoff point PSQI was $>5$, rated diabetic patients who complained of poor sleep quality at 71\% [27]. Tsai et al reported that $34.8 \%$ of Asian T2DM patients had poor sleep quality (global PSQI $>8$ ) [28]. Depending on PSQI score $>8$, Cappuccio et al also found that $47.1 \%$ of T2DM patients were poor sleepers [17]. Additionally, according to PSQI score $\geq 5$, Kara and Kilic, whose PSQI score was $\geq 5$, rated poor sleep quality in diabetic patients at $63.3 \%$ [29]. Cho et al reported the rate of $49 \%$ [30], and Rajendran et al's rate was $69 \%$ [31]. Another study done in USA by Luyster and Dunbar-Jacob [32] reported $55 \%$ of patients to be poor sleepers (PSQI score $>5$ ). The total mean PSQI score of our study was higher than that in these studies. Differences in poor sleep quality may be because of differences in sample size and cultural differences. Additionally, most T2DM patients in our study had severe complications, which heighten poor sleep. 
Table 1. Sleep Quality by Socio-Demographic Characteristics and Biochemistry Values at the NCDEG, 2015 (N = 1,211)

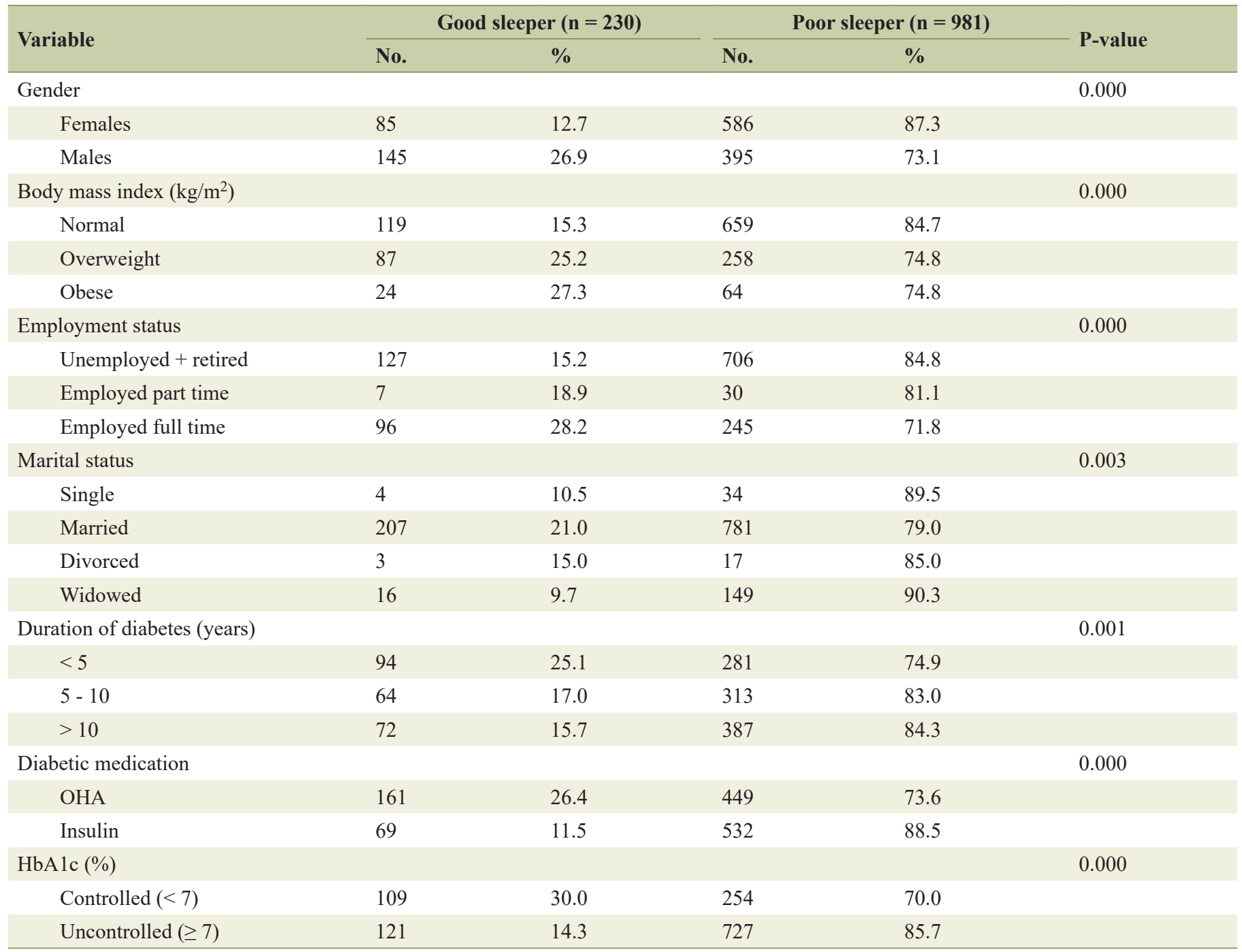

However, the rate in our study is lower than that of Mirghani's study [33], who found that $97.1 \%$ of Sudanese diabetic patients had poor sleep quality. This difference could be explained by the cutoff points used. Mirghani's cutoff point was $\mathrm{PSQI} \geq 5$, while our cutoff point was $\mathrm{PSQI} \geq 8$.

\section{The effect of gender on poor sleep quality in patients with T2DM at the NCDEG}

After adjusting of other variables, we found that female patients had predilection for poor sleep quality more than male patients. Other studies reported similar gender associations as we established in our study [26, 28]. Cho et al [30] reported that female patients were 1.6 times more likely to have poor sleep quality which is lower than our result $(\mathrm{OR}=2.88)$. Compared to our result, Conway et al's study [34] determined that the OR was 2.55 for females compared to males.

However, the study by Rajendran et al [31] found no as- sociation between gender and poor sleep quality.

Effect of smoking habits on poor sleep quality in patients with T2DM at the NCDEG

We showed that a relationship between poor sleep quality and smoking exists. Consistent with our study is that of Chao et al [35] which reported that smoker diabetic patients were 1.07 times more likely to suffer from poor sleep quality. Also, Kachi et al [36] found a similar result. This likelihood of smoker diabetic patients to suffer from poor sleep quality is most likely because of the effect of nicotine consumption on the brain, as nicotine is a mild stimulant to the central nervous system [37]. This association might be explained by the effect of snoring resultant from reduction in breathing (hypopnea) and decrease in oxygen saturation because of smoking $[35,36]$.

Nevertheless, some studies like Li et al's [38] and Coogan et al's [39] did not link smoking with sleep quality. They found 
Table 2. Factors Independently Related to Sleep Quality Using Multivariate Logistic Regression Analysis, the NCDEG, 2015

\begin{tabular}{|c|c|c|}
\hline Variable & Adjusted OR & P-value \\
\hline \multicolumn{3}{|l|}{ Gender } \\
\hline Males $^{\mathrm{a}}$ & 1 & 0.000 \\
\hline Females & 2.88 & \\
\hline \multicolumn{3}{|l|}{ Smoking } \\
\hline Non-smokers ${ }^{\mathrm{a}}$ & 1 & 0.317 \\
\hline Ex-smokers & 1.36 & 0.001 \\
\hline Smokers & 1.92 & \\
\hline \multicolumn{3}{|l|}{ Employment status } \\
\hline Employed full time & 1 & \\
\hline Employed part time & 1.71 & 0.248 \\
\hline Unemployed & 1.69 & 0.007 \\
\hline \multicolumn{3}{|l|}{ Diabetic medication } \\
\hline $\mathrm{OHA}^{\mathrm{a}}$ & 1 & \\
\hline Insulin & 2.17 & 0.000 \\
\hline \multicolumn{3}{|l|}{ HbA1c $(\%)$} \\
\hline Controlled $(<7)^{\mathrm{a}}$ & 1 & 0.000 \\
\hline Uncontrolled $(\geq 7)$ & 2.13 & \\
\hline
\end{tabular}

a. Reference group.

no differences in smoking before going to sleep, snoring, and breathing difficulties during the night $[17,40]$.

\section{Effect of occupational status on poor sleep quality in pa- tients with T2DM who attend the NCDEG}

Our study found that poor sleep quality was higher $(\mathrm{OR}=1.69)$ in unemployed diabetic patients, as compared to employed patients. Yet, no studies to investigate the association between sleep quality and occupational status among diabetic patients were found.

Unemployment leads to psychological disturbance, such as anxiety, low self-esteem, and depression. Such outcomes may consequently materialize into inefficient sleep amount and quality $[41,42]$. This accounts for the high rate of poor sleep quality in the unemployed group in this research.

\section{Association between glycemic index and sleep quality}

Our study significantly correlated glycemic control with sleep quality $(\mathrm{OR}=2.13)$. Tsai et al [28] reported the presence of an inverse correlation between HbA1c and sleep quality. This suggests that glycemic control improves when sleep quality becomes better.

Vigg et al [27] also found a significant positive association between glycemic control and sleep quality and quantity.

According to PSQI score, Cappuccio et al's [17] study showed that a statistically significant difference existed be- tween how poor glycemic control and good glycemic control relate to sleep. Diabetic patients with poor glycemic control had poor sleep quality. This association might be explained by the fact that half of diabetic patients with poor glycemic control may suffer from painful diabetic neuropathy and osmotic diabetic symptoms, thus affecting their sleep quality by frequently visiting the bathroom during the night [40].

Contrary to our result, however, Rajendran et al [31], Mirghani [33] and Cho et al [30] found no significant association between glycemic control and sleep quality.

Higher average age of our research sample, compared to other studies, as well as cultural factors may explain the adversity.

This study showed that diabetic patients on insulin treatment were 2.17 times more likely to complain of poor sleep quality compared to patients receiving OHA only. This result is similar to Cappuccio et al's [17], which reported that insulin users complained of poor sleep quality more often than those on OHA use only.

Rajendran et al [31] did not find significant associations between sleep quality and the type of treatment of diabetes. Social and environmental factors, in addition to the sample size, may account for the explanation.

Although we found significant associations between BMI and sleep quality, those associations did not materialize into significant rates after applying logistic regression. This, however, differs from some studies which found significant associations $[17,35]$.

\section{Conclusion}

In our series, poor sleep quality is prevalent. Females, smokers, unemployed, insulin users and uncontrolled diabetic patients have significant poor sleep quality. Poor sleep quality is associated with poor glycemic control.

\section{Recommendations}

Results of the present study call for increasing the awareness of health care professionals regarding the poor sleep quality of patients with T2DM and its possible adverse effect on glycemic control.

\section{Study limitations}

The PSQI questionnaire is a measure for night sleep not daytime sleep. The study also lacks a control group. Other limitations include the lack of information on psychiatric medications, and the abundance of obesity in our sample which, on its own, could contribute to sleep disturbances.

\section{Conflict of Interest}

The authors declare that there is no conflict of interest that 
could be perceived as prejudicing the impartiality of the review.

\section{Funding}

This research did not receive any specific grant from any funding agency in the public, commercial or not-for-profit sector.

\section{References}

1. Hu FB. Globalization of diabetes: the role of diet, lifestyle, and genes. Diabetes Care. 2011;34(6):1249-1257.

2. Zimmet P, Alberti KG, Shaw J. Global and societal implications of the diabetes epidemic. Nature. 2001;414(6865):782-787.

3. Ajlouni K, Jaddou H, Batieha A. Diabetes and impaired glucose tolerance in Jordan: prevalence and associated risk factors. J Intern Med. 1998;244(4):317-323.

4. Ajlouni K, Khader YS, Batieha A, Ajlouni H, El-Khateeb $\mathrm{M}$. An increase in prevalence of diabetes mellitus in Jordan over 10 years. J Diabetes Complications. 2008;22(5):317324.

5. World Health Organization. WHO technical meeting on sleep and health. Report. World Health Organization. 2004.

6. O'Leary K, Small BJ, Panaite V, Bylsma LM, Rottenberg J. Sleep quality in healthy and mood-disordered persons predicts daily life emotional reactivity. Cogn Emot. 2017;31(3):435-443.

7. Iglowstein I, Jenni OG, Molinari L, Largo RH. Sleep duration from infancy to adolescence: reference values and generational trends. Pediatrics. 2003;111(2):302-307.

8. Hiestand DM, Britz P, Goldman M, Phillips B. Prevalence of symptoms and risk of sleep apnea in the US population: Results from the national sleep foundation sleep in America 2005 poll. Chest. 2006;130(3):780-786.

9. Hirshkowitz M, Whiton K, Albert SM, Alessi C, Bruni O, DonCarlos L, Hazen N, et al. National Sleep Foundation's sleep time duration recommendations: methodology and results summary. Sleep Health. 2015;1(1):40-43.

10. Altevogt BM, Colten HR. Sleep disorders and sleep deprivation: an unmet public health problem. National Academies Press. 2006.

11. Trenell MI, Marshall NS, Rogers NL. Sleep and metabolic control: waking to a problem? Clin Exp Pharmacol Physiol. 2007;34(1-2):1-9.

12. Gottlieb DJ, Punjabi NM, Newman AB, Resnick HE, Redline S, Baldwin CM, Nieto FJ. Association of sleep time with diabetes mellitus and impaired glucose tolerance. Arch Intern Med. 2005;165(8):863-867.

13. Spiegel K, Leproult R, Van Cauter E. Impact of sleep debt on metabolic and endocrine function. Lancet. 1999;354(9188):1435-1439.

14. Lucassen EA, Rother KI, Cizza G. Interacting epidemics? Sleep curtailment, insulin resistance, and obesity. Ann N Y Acad Sci. 2012;1264:110-134.

15. Yaggi HK, Araujo AB, McKinlay JB. Sleep duration as a risk factor for the development of type 2 diabetes. Diabe- tes Care. 2006;29(3):657-661.

16. Holliday EG, Magee CA, Kritharides L, Banks E, Attia J. Short sleep duration is associated with risk of future diabetes but not cardiovascular disease: a prospective study and meta-analysis. PLoS One. 2013;8(11):e82305.

17. Cappuccio FP, D'Elia L, Strazzullo P, Miller MA. Quantity and quality of sleep and incidence of type 2 diabetes: a systematic review and meta-analysis. Diabetes Care. 2010;33(2):414-420.

18. Ohkuma T, Fujii H, Iwase M, Ogata-Kaizu S, Ide H, Kikuchi Y, Idewaki Y, et al. Association between sleep duration and urinary albumin excretion in patients with type 2 diabetes: the Fukuoka diabetes registry. PLoS One. 2013;8(11):e78968.

19. Tamakoshi A, Ohno Y, JACC Study Group. Self-reported sleep duration as a predictor of all-cause mortality: results from the JACC study, Japan. Sleep. 2004;27(1):51-54.

20. Knutson KL. Impact of sleep and sleep loss on glucose homeostasis and appetite regulation. Sleep Med Clin. 2007;2(2):187-197.

21. Metcalfe C. Biostatistics: a foundation for analysis in the health sciences. 7th edn. Wayne W. Daniel, Wiley, 1999. No. of pages: xiv+ 755+ appendices.

22. Suleiman KH, Yates BC, Berger AM, Pozehl B, Meza J. Translating the Pittsburgh Sleep Quality Index into Arabic. West J Nurs Res. 2010;32(2):250-268.

23. Suleiman K, Hadid LA, Duhni A. Psychometric Testing of the Arabic version of the Pittsburgh Sleep Quality Index (A-PSQI) among Coronary Artery Disease Patients in Jordan. Journal of Natural Sciences Research. 2012:2(8):15-20.

24. Lou P, Qin Y, Zhang P, Chen P, Zhang L, Chang G, Li T, et al. Association of sleep quality and quality of life in type 2 diabetes mellitus: a cross-sectional study in China. Diabetes Res Clin Pract. 2015;107(1):69-76.

25. Suarez EC. Self-reported symptoms of sleep disturbance and inflammation, coagulation, insulin resistance and psychosocial distress: evidence for gender disparity. Brain Behav Immun. 2008;22(6):960-968.

26. Seligowski AV, Pless Kaiser AP, Niles BL, Mori DL, King LA, King DW. Sleep quality as a potential mediator between psychological distress and diabetes quality of life in veterans with type 2 diabetes. J Clin Psychol. 2013;69(10):1121-1131.

27. Vigg A, Vigg A, Vigg A. Sleep in Type 2 diabetes. J Assoc Physicians India. 2003;51:479-481.

28. Tsai YW, Kann NH, Tung TH, Chao YJ, Lin CJ, Chang $\mathrm{KC}$, Chang SS, et al. Impact of subjective sleep quality on glycemic control in type 2 diabetes mellitus. Fam Pract. 2012;29(1):30-35.

29. Kara B, Kilic O. Predictors of poor sleep quality and excessive daytime sleepiness in Turkish adults with type 2 diabetes. J Clin Nurs. 2015;24(9-10):1436-1439.

30. Cho EH, Lee H, Ryu OH, Choi MG, Kim SW. Sleep disturbances and glucoregulation in patients with type 2 diabetes. J Korean Med Sci. 2014;29(2):243-247.

31. Rajendran A, Parthsarathy S, Tamilselvan B, Seshadri $\mathrm{KG}$, Shuaib M. Prevalence and correlates of disordered sleep in southeast asian indians with type 2 diabetes. Dia- 
betes Metab J. 2012;36(1):70-76.

32. Luyster FS, Dunbar-Jacob J. Sleep quality and quality of life in adults with type 2 diabetes. Diabetes Educ. 2011;37(3):347-355.

33. Hyder Osman Mirghani. Sleep quality effects on glycemic control among Sudanese patients with type 2 diabetes -A case-control study. Basic Research Journal of Medicine and Clinical Sciences. 2015;4(12):258-261.

34. Conway SG, Roizenblatt SS, Palombini L, Castro LS, Bittencourt LR, Silva RS, Tufik S. Effect of smoking habits on sleep. Braz J Med Biol Res. 2008;41(8):722-727.

35. Chao CY, Wu JS, Yang YC, Shih CC, Wang RH, Lu FH, Chang CJ. Sleep duration is a potential risk factor for newly diagnosed type 2 diabetes mellitus. Metabolism. 2011;60(6):799-804.

36. Kachi Y, Ohwaki K, Yano E. Association of sleep duration with untreated diabetes in Japanese men. Sleep Med. 2012;13(3):307-309.

37. Newhouse PA, Potter A, Singh A. Effects of nicotinic stimulation on cognitive performance. Curr Opin Pharmacol. 2004;4(1):36-46.

38. Li Y, Gao X, Winkelman JW, Cespedes EM, Jackson CL, Walters AS, Schernhammer E, et al. Association between sleeping difficulty and type 2 diabetes in women. Diabetologia. 2016;59(4):1-9.

39. Coogan A, Vesa J, Voinescu B. Self-reported diurnal preference and sleep disturbance in type 2 diabetes mellitus. Acta Endocrinologica-Bucharest. 2011;7(1):69-82.

40. Zelman DC, Brandenburg NA, Gore M. Sleep impairment in patients with painful diabetic peripheral neuropathy. Clin J Pain. 2006;22(8):681-685.

41. Basta M, Chrousos GP, Vela-Bueno A, Vgontzas AN. Chronic insomnia and stress system. Sleep Med Clin. 2007;2(2):279-291.

42. Cheung T, Yip PS. Depression, Anxiety and Symptoms of Stress among Hong Kong Nurses: A Cross-sectional Study. Int J Environ Res Public Health. 2015;12(9):1107211100 . 